\title{
Stainless steel brackets failure rate after topical fluoride application in etching procedures
}

\author{
Ali R AL-KHATIB*
}

\begin{abstract}
Enamel demineralization that occurs adjacent to directly bonded orthodontic attachments is of great concern to orthodontists. One of the suggested procedures to overcome this problem is to use topical fluoride treatment after acid etching. The purpose of this study was to evaluate the failure rate of stainless steel bracket with metal mash base after topical application of $(1.1 \%)$ neutral sodium fluoride gel after (37\%) phosphoric acid etching. Twenty patients with full maxillary and mandibular "0.018" standard edgewise fixed appliances were included. Maxillary right, mandibular left sides were received the topical sodium fluoride gel application after etching with (37\%) $\mathrm{H}_{3} \mathrm{PO}_{4}$ for (30) seconds. The gel was applied for (4) minutes after etching, then rinse with air and water stream for (5) seconds; while in the contralateral sides the bonding was done conventionally. The bonding adhesive was the No-Mix chemical cure adhesive. The follow-up period was (12-15) months. The results showed that brackets failure rate in fluoridated group did not differ significantly from the non-fluoridated one. Hence the $(1.1 \%)$ neutral sodium fluoride may have a clinical application in preventing demineralization that occurred around and under orthodontic brackets without any significant increase in failure rate of stainless steel brackets.
\end{abstract}

Key Words: Failure rate, topical fluoride.

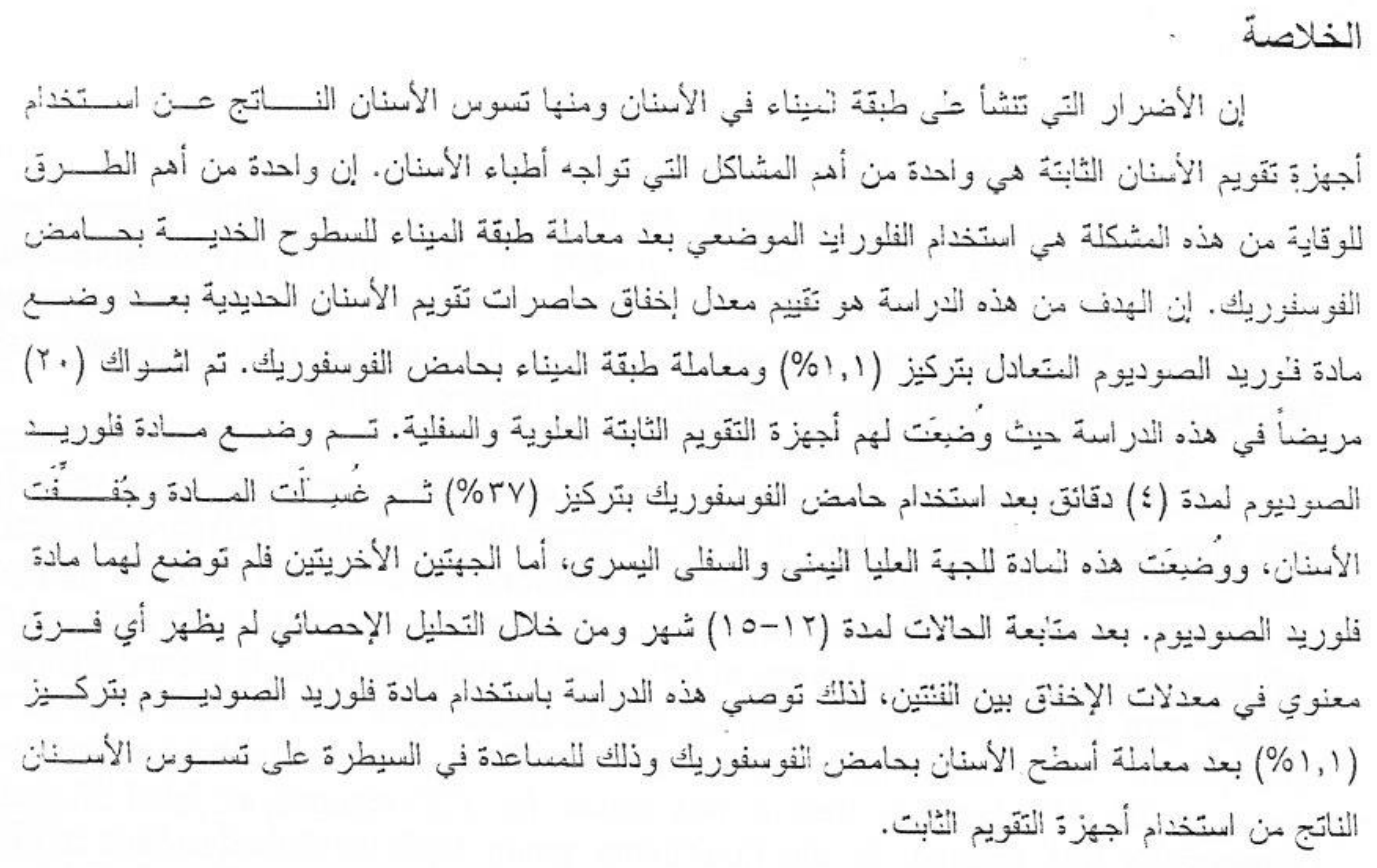

** Ali Rajeh AL-KHATIB; BDS, MSc: Lecturer. Department of Pedodontics, Orthodontics and Preventive Dentistry, College of Dentistry, University of Mfosul, Mosul, IRAQ. 


\section{INTRODUCTION}

During orthodontic bonding procedure, teeth are etched so as to alter the enamel surface in a pattern that enhance the mechanical adhesion between enamel and the bonding resin ${ }^{(1)}$. The etched enamel surface is more susceptible to dental caries; this is clearly found under and near the fixed orhodontic attachments as the difficulty in cleaning teeth is an additional factor for the accumulation of dental plaque with subsequent demineralization of the involved teeth ${ }^{(2)}$,

Many attempts to offset these effects have been carried out; one of them is the topical fluoride application ${ }^{(3)}$. It is widely accepted that the fluoride compounds exert anticariogenic properties. The mechanism of fluoride action is multifactorial one: it is either by increasing the resistance of enamel to acids (throughout the formation of calcium fluoride of fluorapatite crystals) in spite of those which removed by the acid, or interfere with the metabolism of the cariogenic microorganisms ${ }^{(4,5)}$

There are (3) main methods of topical fluoride application during bonding procedures were considered, which are either before etching ${ }^{(6)}$, during etching ${ }^{(7)}$, or after etching with phosphoric acid ${ }^{(1)}$.

The orthodontic practitioners always prefer to do bonding work that provide maximum bonding strength for their brackets with minimal caries involvement of the teeth. Many laboratory studies ${ }^{(8)}$ reported that the application of fluoride compounds after etching shown an increase in enamel fluoride uptake, making the enamel more resistant to acid dissolution factors. Also the measurable bonding strength was an adequate one.

In spite of that, little clinical trials were carried out on patients to assess the bracket failure due to fluoride using within the orthodontic treatment ${ }^{(9)}$.

This research is aimed to determine whether the topical application of (1.1\%) neutral sodium fluoride after acid etching procedures would significantly affect the failure rate of stainless steel orthodontic brackets during orthodontic treatment.

\section{MATERIALS AND METHODS}

In this research, (20) patients requiring full fixed orthodontic therapy were involved. Participants were at least (12) years of age with no any massive dental restoration on the involved teeth. Also the teeth should have sufficient clinical crown length to allow orhodontic brackets placement. The patient did not receive any additional topical fluoride supplement during the research period.

The maxillary right and mandibular left quadrants were designated to receive the topical fluoride application, while the matched contralateral quadrants served as the non-fluoridated group, so that (80) brackets were involved, (40) for each group. The premolars were the teeth of choice in orthodontic extraction for all of the patients.

Each patient received a prophylactic polishing for his or her teeth with a slurry of non-fluoride pumice and water in slow speed handpiece (Quayle Dental Co.) with rubber cup (Swiss Co.) then each of the involved teeth was etched with (37\%) phosphoric acid (taken from No-Mix Master-Dent orthodontic bracket adhesive system) for (30) seconds, then it was rinsed for (15) seconds, air dried till chalky appearance was created. In the fluoridated group teeth the etched surface received $(1.1 \%)$ neutral sodium fluoride gel (Flor-Opal Ultradent Products, Inc) which was topically applied for (4) minutes, then it was rinsed with water and air stream for just (5) seconds. 
A thin layer of the primer was applied on both etched surface and the base of brackets, then the No-Mix chemical cure achesive system was placed on bracket base. The stainless steel twin, (0.018) standard edgewise brackets with mesh base (Dentaurum Co.) were used in this study. After that, the bracket was adapted to its position, and the access was removed with dental probe (Dentaurum Co.).

Patients were instructed to maintain his oral hygiene measures (tooth orushing) normally and to inform the operator by the bracket failure immediately. They were seen at (4) week intervals throughout the course of the study, which extended (12-15) months of an active therapy.

When the patient was attended within failed bracket, the date, tooth number and side were recorded. The failed one was replaced for the patient by new one and it was attached according to the conventional bonding procedures. The failure side on tooth surface was examined by magnifying lens $(5 \times$ power $)$ and the mesh base was examined under light microscope at ( $40 \times$ power) so as to record the adhesive remnant index ${ }^{(11)}$ as score $0=$ no adhesive left on the tooth, score $1=$ less than half the adhesive lef. on the tooth, score 2 = more thar half the adhesive left on the tooth, and score $3=$ all the adhesive left on the tooth.

\section{RESULTS}

The number and frequency of failures for sample groups and for the upper and lower arches individually are presented in tables (1) and (2).

Table (1): Failure rate of bonded stainless steel jrackets for the non-fluoridated group

\begin{tabular}{|c|c|c|c|c|c|c|c|}
\hline \multirow[b]{2}{*}{ Ar.ch } & \multirow{2}{*}{ 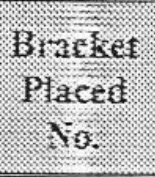 } & \multirow[b]{2}{*}{ T (000) } & \multicolumn{4}{|c|}{ Fio. Friled } & \multirow{2}{*}{$\begin{array}{l}\text { fercent } \\
\text { franled }\end{array}$} \\
\hline & & & $\begin{array}{l}1-4 \\
\text { Weeks }\end{array}$ & $\begin{array}{l}5-9 \\
\text { Weelis }\end{array}$ & 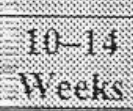 & $\begin{array}{l}\text { 11 - Oret } \\
\text { Wrekis }\end{array}$ & \\
\hline \multirow{4}{*}{$\frac{\frac{\pi}{3}}{\frac{\pi}{2}}$} & \multirow{4}{*}{20} & $\begin{array}{l}\text { Central } \\
\text { Incisor }\end{array}$ & I & 1 & 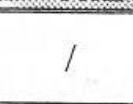 & 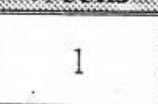 & 5 \\
\hline & & $\begin{array}{l}\text { Lateral } \\
\text { Incisor }\end{array}$ & I & 1 & / & I & 0 \\
\hline & & Canine & 1 & / & I & / & 5 \\
\hline & & Premolar & I & 2 & I & 1 & 15 \\
\hline \multicolumn{3}{|c|}{ ( 30.21 ) } & 1 & 2 & 1 & 2 & 25 \\
\hline \multirow{4}{*}{$\frac{\frac{3}{2}}{\frac{3}{2}}$} & \multirow{4}{*}{20} & $\begin{array}{l}\text { Central } \\
\text { Incisor }\end{array}$ & 1 & 1 & / & 1 & 0 \\
\hline & & $\begin{array}{l}\text { Lateral } \\
\text { Incisor }\end{array}$ & 1 & / & 2 & 1 & 10 \\
\hline & & Canine & 1 & 1 & I & I & 0 \\
\hline & & Premolar & I & 1 & 1 & 1 & 5 \\
\hline & Tol:t & & I & I & 3 & I & 15 \\
\hline
\end{tabular}


Table (2): Failure rate of bonded stainless steel brackets for the fluoridated group

\begin{tabular}{|c|c|c|c|c|c|c|c|}
\hline \multirow[b]{2}{*}{ Arcel } & \multirow{2}{*}{$\begin{array}{l}\text { Brackef } \\
\text { Placet } \\
\text { lov. }\end{array}$} & \multirow[b]{2}{*}{ 180.011: } & \multicolumn{4}{|c|}{ No. Friziled } & \multirow{2}{*}{ ferceri } \\
\hline & & & 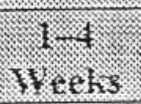 & $\begin{array}{l}5.9 \\
\text { Hedus }\end{array}$ & $\begin{array}{l}\text { is- if } \\
\text { 11eeks }\end{array}$ & if 1 orer & \\
\hline \multirow{4}{*}{$\frac{\frac{\pi}{2}}{\frac{2}{2}}$} & \multirow{4}{*}{20} & $\begin{array}{l}\text { Central } \\
\text { Incisor }\end{array}$ & 1 & 1 & 1 & 1 & 0 \\
\hline & & $\begin{array}{l}\text { Lateral } \\
\text { Incisor }\end{array}$ & 1 & 2 & 1 & 1 & 15 \\
\hline & & Canine & 1 & 1 & 1 & 1 & 5 \\
\hline & & Premolar & 2 & 1 & 1 & 1 & 15 \\
\hline \multicolumn{3}{|c|}{ Totut } & 2 & 2 & 2 & 1 & 30 \\
\hline \multirow{4}{*}{$\frac{\frac{3}{3}}{\frac{3}{3}}$} & \multirow{4}{*}{20} & $\begin{array}{l}\text { Central } \\
\text { Incisor }\end{array}$ & l & 1 & i & 1 & 10 \\
\hline & & $\begin{array}{l}\text { Lateral } \\
\text { Incisor }\end{array}$ & 2 & ! & 1 & I & 10 \\
\hline & & Canine & 1 & 1 & 1 & 1 & 5 \\
\hline & & Premolar & 1 & 1 & 1 & 1 & 5 \\
\hline \multicolumn{3}{|c|}{ Tlatetl } & 2 & 1 & 1 & 1 & 25 \\
\hline
\end{tabular}

In non-fluoridated group the maxillary premolars appeared to have the highest failure rate, while both the maxillary lateral incisors and premolars have the highest percentages at the fluoridated one. In the mandibular arch the central and lateral incisors having the highest failure rate percentages in the fluoridated group.

The difference between study groups appear to be non significant at $p<0.05$ for both maxillary and mandibular dental arches. This was shown in table (3).

Table (3): Difference in failure rate between study groups

\begin{tabular}{|c|c|c|c|}
\hline A. El: & 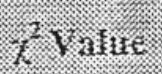 & 3.8 & p. V. Iftue \\
\hline 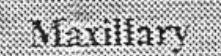 & 0.107 & 1 & N.S \\
\hline 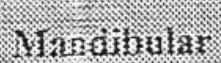 & 0.500 & 1 & $\mathrm{~N}: \mathrm{S}$ \\
\hline
\end{tabular}

$p<0.05$ significant level; N.S $=$ Non-significant.

Likewise, the results of ARI indicated that most of the failed brackets on the fluoridated group were at score 0,1 and 2 . Little have been recorded within score 3 . This is also appeared in relation to those of the non-fluoridated one. These results were shown in table (4). 
Table (4): Distribution of ARI scores for the study groups

\begin{tabular}{|c|c|c|c|c|c|c|c|c|}
\hline \multirow{2}{*}{ ( irdis } & \multicolumn{4}{|c|}{ 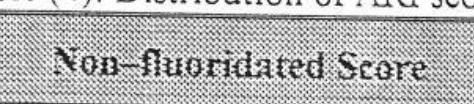 } & \multicolumn{4}{|c|}{ Ilatoridinted Seare } \\
\hline & 的. & ; & 2 & 3 & f & 1 & 2 & 3 \\
\hline Iizanila & 2 & 0 & 2 & 1 & 3 & 3 & 0 & 0 \\
\hline Harzelizale & 0 & 1 & 2 & 0 & 1 & 2 & 2 & 0 \\
\hline
\end{tabular}

\section{DISCUSSION}

The introduction and development of different fluoride products has significantly reduce the problem of dental caries (11). Many of these products are depend on patient cooperation, but, in orthodontic practice, the most effective method is that which is independent of patient compliance, as they should be specific to areas under and adjacent to the fixed attachment ${ }^{(9)}$.

Previous studies ${ }^{(12,13)}$ were reported that topical fluoride will occupy the inter-presmatic spaces that produced by phosphoric acid leading to significant reduction of bonding strength. Another investigators ${ }^{(5)}$ indicated that the shear or tensile strength of bonding agents increased after the fluoridation of the etched surface of the involved teeth. Contrary to these findings, Hirce et al. ${ }^{(12)}$, Bishara et al. ${ }^{(1)}$, and Büyükyilmaz et al. (14) reported no significant difference in bonding strength due to topical fluoride application after acid etching. All of these conclusions were recorded after using different concentrations and types of topical fluoride like $(2 \%),(4 \%)$ of acidulated sodium fluoride ${ }^{(1)},(8 \%)$ stannous fluoride ${ }^{(12)}$ and even $(1 \%),(4 \%)$ titanium tetrafluoride, in different phosphoric acid concentrations $(37 \%-50 \%)$ in same etching time ( 1 minute).

In front of this large number of conflicting laboratory investigations, little was carried out to assess these findings on clinical practice. This research is a clinical trial that was carried out in a small group of orthodontic patients to evaluate the failure rate of their stainless steel brackets after topical (1.1\%) sodium fluoride application.

It has been clear that the application of acidic fluoride-containing solution to the etched enamel results in formation of $\mathrm{CaF}_{2}$ as a predominant reaction products ${ }^{(15)}$. In clinical work the acid etchant should be washed out with water for at least (10) seconds before the application bonding resin. This intensive washing procedure will remove the bulk of alkali-soluble reaction products $\left(\mathrm{CaF}_{2}\right)$ from the enamel surface making the addition of fluoride to the etching solution have little protective effect ${ }^{(4)}$. The application of $(1.1 \%)$ neutral sodium fluoride in this study was carried out after the completion of acid etching procedure, as the complete removing of the monocalcium phosphate monohydrate layer was done by the intensive washing action of the water leaving a clean enamel available for receiving the fluoride gel ${ }^{(16)}$. The fluoridation time increased in this study to (4) minutes to provide the maximum contact time for the fluoride uptake by the etchant areas. Also the washing time of the fluoride gel minimized to (5) seconds to decrease the loss of $\mathrm{CaF}_{2}$ ions. These ions and the calcium fluorapatite one which formed after that will act as a slow fluoride releasing agents that make the enamel more resistant to the dissolution ${ }^{(17)}$. 
In this study, the overall clinical bond failure rates between the two groups were not significantly different. In the fluoridated group the failures appear to be favourably comparable even with those reports using different conventional bonding technique ${ }^{(18.19)}$, but not with those who use the fluoridated adhesive system ${ }^{(8.9)}$.

Underwood et al. ${ }^{(8)}$, Sonis and Snell ${ }^{(9)}$ assess the failure rate of stainless steel bracket after using the fluoridated bonding systems and reported a high percentage of bracket failures of the premolar region. In our practice the failures that occurred in premolars could either due to disturb setting of bonding site or even due to occlusal interference as $(80 \%)$ of bonding failures occurred within the first (2) weeks after bracket placement.

The majority of failures were at resin/ resin interface. This indicated that the fluoride did not disturb the structural integrity of the enamel / resin interaction throughout the investigation period, unlike others who found that enamel / resin interface was the major failure site ${ }^{(20)}$

\section{CONCLUSIONS AND RECOMMENDATIONS}

1. The application of $(1.1 \%)$ neutral sodium fluoride after acid etching was found to provide bracket retention rates similar to those who did not receive any fluoride application curing etching or bonding procedures. The extended working times afforded by this technique were considered acvantageous in allowing for precise protection of enamel from demineralization.

2. The primary cause of failure for both arches was occlusal interference.

3. Occurrence of cohesive failure rather than adhesive indicates that fluoride did not disturb the integrity for the interaction between eramel / resin interface.

t. The application of $(1.1 \%)$ neutral sodium fluorice appear to have an important role during procedures.

5. More investigation either laboratory or clinical one are indicated to assess the role of different types and concentrations of fluoride either on bracket retention or on adhesive structural integrity, and enamel demineralization during orthodontic treatment.

\section{REFERENCES}

1. Bishara SE, Ehan D, Abadir EA. The effect on the bonding strength of orthodontic brackets of fluoride application after etching. Am J Orthod Dentofac Orthop. 1989; Mar: 259-260.

2. Gwinnett IA, Geen F. Plaque distribution of bonded brackets. Am J Orthod. 1979; 75: 667 .

3. Low T, Von Fraunhofer JA, Winter GB. The bonding of polymer fissure sealant to topical fluoride treated teeth. J Oral Rehabil. 1975; 2: 303-307.

4. Thornton JB, Rerief DH, Bradley GL, Densy FR. The effect of fluoride in phosphoric acid on enamel fluoride uptake and the tensile bond strength of an orthodontic bonding resin. Am J Orthod Dentofac Orthop. 1986; 90: 91-101.

5. Garcia-Godoy F, Hubbard GW, Storey AT. Efrect of a fluoridated etching gel on enamel morphology and shear bond strength of orthodontic bracket. Am J Orthod Dentofac Orthop. 1991; 100: 163-170. 
6. Wang WN, Sheen DH. The effect of pre-treatment with fluoride on the tensile strength of orthodontic bonding. Angle Orthod. 1991; 61: 31-34.

7. Grajower R, Glick A, Gedalia I, Kachavi D. Tensile strength of the bond between resin to enamel etched with phosphoric acid containing fluoride. J Oral Rehabil. 1979; 6: 267-272.

8. Sonis $\Lambda \mathrm{L}$, Sncll $\mathrm{W}$. An evaluation of fluoride releasing visible light-activated bonding system for orthodontic bracket placement. Am. J (Orthod Dentofac Orthop). 1989; 95: 306-311.

9. Underwood ML, Rawls RN, Zimmerman FB. Clinical evaluation of a fluoride exchanging resin as an orthodontic adhesive. Am. J ()rthod Dente)fac (Orthop). 1989; 96: 93-99.

10. Artun J, Bergland S. Clinical trials with crystal growth conditioning as an alternative to acid etch enamel pre-treatment. Am.J Orthod. 1984; 85: 333-340.

11. Khamreo TY, Jazrawi KII. Ilas the reduced concentration and time of application effect on the anti-caries potential of APF gel? Iraqi.J ()ral Dent Sci. 2002; 1(1): 69-81.

12. Haric JD, Howard-Sather A, Edmonds YS. The effect of topical fluorides after acid etching of enamel on the bond strength of directly bonded orthodontic brackets. Am. J Orthod De'mtofac (Orthop. 1980; Oct: 444-452.

13. Grajower R, Glick A, Gedalia I, Kachavi D. Tensile strength of the bond between resin to enamel etched with phosphoric acid containing fluoride. J Oral Rehabil. 1979; 6: 267-272.

14. Büyükyilmaz T, Tangugsorn V, Gaard B, Arends J, Ruben J, Ila G. The effect of titanium tetrafluoride $\left(\mathrm{TiF}_{4}\right)$ application around orthodontic brackets. Am. J Orthod Dentofac Orthop. 1994; 105: 293-296.

15. Richardson 13. Fixation of topically applied fluoride in enamel. J Dent Res. 1967; 46: 87-91

16. Chow IC, Brown WE. Phosphoric acid conditioning of tecth for pit and fissure sealants. J Dent Res: 1973; 52: 1158.

17. Rølla $G$. The role of calcium fluoride in the cariostatic mechanism of fluoride. Acta Odontol Scand. 1988; 46: 341-345.

18. Zachrisson $13 \mathrm{U}$. A post-treatment evaluation of direct bonding in orthodontics. Am J Orthod. 1977; 71: 173-189.

19. Geiger L, Gorelick L, Gwinnett AJ. Bond failure rates of facial and lingual attachments. J Clin Orthod. 1983; 17: 165-169.

20. Fields HW. Bonded resins in orthodontics. Pediatr Dent. 1982; 4: 51-60. 